\title{
Learners' Perceptions of the Life Orientation Curriculum in Fort Beaufort District Eastern Cape in South Africa
}

\author{
Toyin Mary Adewumi \\ School of Further and Continuing Education, Faculty of Education, \\ University of Fort Hare, South Africa \\ Email: toyinadewumi28@gmail.com

\section{Mr. Mike Adendorff} \\ Deputy Director School and Pre-school Teacher Education, \\ Department of Higher Education and Training, Pretoria. South Africa
}

\section{Doi:10.5901/mjss.2014.v5n7p460}

\section{Abstract}

The study explored how learners perceive the Life Orientation programmes. This study is a follow up on research findings which revealed that in spite that many learners felt positive about the subject Life Orientation, which to some extent supports the study conducted by Theron (2008), who found that a sample of Grade 9 township learners valued LO, some of these learners gave the impression that they engaged in risky behaviours that had been discussed in LO, a subject specifically intended to help learners face and cope with problems, and make more sensible, or at least informed, life choices. This raises the question whether learners are being adequately guided, or inadvertently misguided, in their LO lessons. The results of the study showed that in LO, in addition to quite different topics such as career choice, physical education and religion education, the learners had indeed been taught about and made aware of the consequences of social problems like falling pregnant while still at school, drug abuse and the threat of HIV/AIDS. This article represents only a part of this Masters in Education research. The study was located within the interpretivist paradigm and used a qualitative research design in the form of narratives as a strategy of enquiry. The researcher conducted six focus group discussions with learners and held interviews with six teachers and principals. The analysis of the data was done by clustering common themes and writing stories to uncover the main issues that were arising. The issues were then put together as findings for the study. Document analysis and classroom observation were also used to complement findings from the interviews. Generally, this study points to a major issue to be tackled in curriculum development, which is the incorporation of a more effective mechanism for measuring the impact of LO teaching on the learners. It seems that LO may have achieved more in the way of awareness creation in terms of imparting knowledge than it has in bringing about the behavioural changes that are expected. Therefore mere verbal feedback from learners in interviews or focus groups may not be enough to gauge how successfully the LO curriculum is implemented.

Keywords: Life Orientation, curriculum, learners' perceptions

\section{Introduction}

Many learners in South Africa are not adequately guided towards positive self-concept formation or the realisation of their potential. Consequently, they are at risk of growing towards an irresponsible and unfulfilled adulthood in which they may never experience the joy of harmonious relationships with their fellow men and women (Prinsloo, 2005). Such young people may come to have little respect for their own dignity, suffer from negative self-concept, refuse to accept authority, and show little respect for the values, lives or possessions of others. In adulthood they often adopt anti-social attitudes and habits, and may lapse into criminal activities (Prinslo0, 2005:33). In some cases, their lack of emotional stability may contribute to the high rate of violent crime, including rape and murder, reported daily in the South African press (Pretoria News, 2006).

Life Orientation (LO) was introduced as a component of the new national curriculum in 1998, as part of the solution to these and other social problems. It was proposed in line with ideas about health, sex, and reproductive education which would enable learners to understand issues of masculinity and femininity, and which would also make it possible for learners to protect themselves and live healthy lives, free from risks (Coombe, 2002; Department of Education, 2006). Also, according to a proposal from the national Gender Task Team of 1997, LO was introduced in part to serve as a way of curbing sexual violence in schools and enhancing gender equity. Having realised the scope and intensity of this 
problem, the Department of Education of the time endeavoured, through the introduction of an outcomes-based education which aims at enabling learners to demonstrate not only knowledge and skills but also attitudes and values, and in particular through the Life Orientation learning area, to put in place mitigatory programmes which could make a difference in the lives of a new generation of learners. Although the above-mentioned health and sexuality elements were to the fore in the early proposal stages, the eventual LO curriculum was more holistic, and incorporated other aspects of a 'preparation for life' (Coombe, 2002).

Applying a holistic approach, the South African Department of Education of the time viewed LO (2003:3) as the study of self in relation to other individuals and to society. LO had to do (and has had to do since then) with the personal, social, intellectual, emotional, spiritual, motor and physical growth and development of learners, and the way in which these dimensions are interrelated and used in life (Department of Education, 2003). Its concern is the development of self-in-society, and this is intended to help the development of balanced and confident learners who will contribute to a just and democratic society, a productive economy, and a good life for all (Department of Education, 2003). This learning area aims to guide and prepare learners for life, and for its responsibilities and possibilities. LO addresses knowledge, values, attitudes and skills relating to the self, the environment, responsible citizenship, a healthy and productive life, social engagement, recreation, physical activity and career choices. It aims to teach learners to solve problems, to make informed decisions and choices, and to take suitable actions to enable them to live meaningfully and successfully in a rapidly changing society (Department of Education, 2003:3).

The development of LO programmes has brought educators and educational planners to the realisation that the only hope of reaching children at risk lies in a holistic support system (Pretorius, 1998; Engelbrecht, 1998; LeRoux, 1994; Mwamwenda, 2004; Eggen and Kauchak, 1997; DoE, 1992; National Educational Policy Investigation, the National Education Policy Investigation (NEPI), 1993; White Paper on Education and Training (WPET), 1995; Republic of South Africa, 2000). Extensive research completed by researchers from South Africa and countries such as the United States, United Kingdom, and Europe, highlights the need for orientation programmes that will prepare learners adequately for the complex and dynamic life of the 21 $1^{\text {st }}$ century (Pretorius, 1998; Engelbrecht, 1998; LeRoux, 1994; Mwamwenda, 2004; Eggen and Kauchak, 1997; DoE, 1992; National Educational Policy Investigation, the National Education Policy Investigation (NEPI), 1993; White Paper on Education and Training (WPET), 1995; Republic of South Africa, 2000).

However, it appears that the introduction of LO in the curriculum comes with attendant challenges that can threaten to derail it as a solution. For one thing, it appears that many teachers have difficulties in teaching LO programmes which entail discussing personal and societal values and norms with learners (Ahmed, Flisher, Mathews, Mukoma and Janse, 2006). Teachers are expected to find a balance between their own beliefs and the idea that they must sometimes teach material they may believe should not be taught to learners, such as the practice of safe sex (Ahmed et al., 2006). Teachers seem often to be placed in situations where they lack expertise or find themselves 'out of their league', which creates stressful situations for them. This also raises a number of questions for learners, who are in many cases able to sense the incompetence and ineffectiveness of unqualified teachers (Van Deventer and Van Niekerk, 2008:135).

Life Orientation teachers also encounter challenges in their work when they have to deal with learners of diverse personalities who also exhibit different levels of maturity and growth (Wight and Buston, 2003; Landry, Singh and Darroc, 2000). While this occurs naturally among learners, they often encounter several different LO teachers of differing persuasions in the course of their school careers, and may therefore tend to become confused, or even a little unstable themselves (Christiaans, 2006:10). In addition to this complex situation, some teachers are not qualified to handle the subject, and learners at times feel short-changed as a result. Hence some learners question the value attached to LO when it is presented by unqualified teachers, and in consequence they may not put great effort into studying the subject. (Christiaans, 2006:11; Van Deventer, 2009:128). Yet another problem that has been identified is that working with small groups, which tends to be an effective strategy in teaching LO, is hardly possible with large class sizes of up to sixty students in a class, and facilitation of group work is challenging when there is limited space and there are no teacher assistants to manage large classes (Ahmed, Flisher, Mathews, Jansen, Mukoma and Schaalma, 2009:51).

Furthermore, the LO programme remains marginalised as time allocated for it is in practice often used for subjects like Mathematics, which are deemed more important, since LO does not involve external assessment, despite the fact that it is a compulsory subject. The prominent academic Jonathan Jansen went so far as to write, in his popular column in The Times, that Life Orientation will be of no help whatsoever in boosting learners' chances of gaining a place in higher education (Jansen, 2011:40). LO is also widely perceived as a subject not requiring much preparation or skill (Coombe, 2002; Koplan, 2001). Moreover, it appears that learners also show negative attitudes towards the LO programme because they fail to understand its objectives (Rooth, 2005:68).

Concern has therefore been raised regarding the implementation and status of the LO curriculum. Informally, the public and the media have tended to attribute the difficulties encountered by teachers in teaching LO to their having 
difficulty in teaching personal and societal values and norms. However, the problems, as discussed above, seem more wide-ranging. In addition, learners are reported to have difficulties in understanding the terminology, the norms and values, while the teachers struggle to clarify these for them (Ahmed et al., 2006:627).

Some teachers have informally expressed concern that they have been encountering challenges in trying to get a balance between their own beliefs and the idea that they must teach certain material that they believe should not be taught to learners (Ahmed et al., 2009:50-51). There are concerns that students might take things literally and interpret messages about sex as teachers condoning sex as a norm for their age group (Aaro; Flisher and Kaaya, 2006). At times teachers feel that the values they hold are contrary to the content they are expected to teach. This is true in the example of having to teach learners to use condoms, which most teachers feel encourages loose morals. It is in cases like this that teachers who feel this causes promiscuity may teach against the values fostered in the Life Orientation (LO) programmes, (Kaaya, Mukoma, Flisher and Klepp, 2009). This study confirmed this during the interviews with some of the participant LO teachers, school principals and learner focus groups. It was disclosed that some LO teachers shy away from teaching about sensitive topics like sex and HIVIAIDS.

Darius Cornelissen (2009), spokesperson for the National Professional Teachers Organisation of South Africa (NAPTOSA), believes that there is a great deal of concern among teachers about how to teach LO. During the interviews in this study, some of the LO teachers complained that they did know if they were doing the right thing because they had not been trained to teach LO. Teachers have complained that learners are reluctant to discuss their personal values and beliefs in the presence of their peers (Gallant and Maticka-Tyndale, 2004). There may well be strategies for dealing with such challenges, but teachers are often unaware of these. The Development Bank of Southern Africa education policy analyst, Graeme Bloch (2009), is of the view that there is very little realistic support for teachers in their classroom practice.

\section{Method}

This research study was qualitative in nature, and used a case study design based largely on interviews and classroom observation. This method was chosen on the strength of its ability to provide an in-depth and detailed account of the phenomenon under study, enabling the researcher to discover things that might not have become apparent through more superficial research (Denscombe, 2001). This study was located within the multiple case study category. It was not the purpose of this study to gain an in-depth understanding of Life Orientation (LO) implementation in the Fort Beaufort schools because they stand out in any particular way, or to develop law-like generalisations based on the findings, but to provide insight into the phenomenon or general condition of implementing the national Life Orientation (LO) curriculum in South Africa, hence justifying the adopted research design. Therefore in this research, where the objective was to investigate the implementation of the Life Orientation (LO) curriculum, the researcher used the cases of Life Orientation (LO) teaching and learning in six Fort Beaufort high schools to gain an in-depth picture of the implementation of the Life Orientation (LO) curriculum.

A case study design was followed since it gives an in-depth and detailed account of the phenomenon and hence enables the researcher to discover things that might not have become apparent through more superficial research (Denscombe, 2001). It focuses on individual actors or groups of actors, and seeks to understand their perceptions of events in order to understand complex social phenomena and to provide a holistic and meaningful picture of real-life events, such as individual life cycles, and organisational and managerial processes (Yin, 2003).

\subsection{Research instruments}

Four data collection methods were used during the investigation. The study used focus group and semi-structured individual interviews, classroom observation and document analysis. Focus group interviews were used to solicit learners' opinions and perceptions on the implementation of the Life Orientation curriculum. The focus was on the knowledge learners had acquired on drug abuse, the influence of sexuality education on learners' attitudes or behaviour, and ways in which knowledge gained through HIVIAIDS education was of value to learners. Focus group interviews were also selected because they allowed interaction between participants that highlighted their shared or idiosyncratic views of the world, the language they used about the issue in question, and their values and beliefs about the situation (Kritzinger, 1995). In this study, this method was used as a complement to other methods (Morgan, 1998), especially in triangulation with the individual interviews with educators and principals.

In this research, documents were analysed, partly in order to fill gaps that were left by the interviews and observation methods. Document analysis also provided the researcher with the opportunity to verify some identified 
issues with the respondents during the later interviews, and thus minimised the risk of imposing personal inferential interpretations of what was found in the documents (Chisaka and Vakalisa, 2000). The study reviewed documents relevant to the study, which included lesson plans, and learners' and teachers' profiles. Information from these documents provided data that supplemented the data gained through interviews and observation. These documents were randomly selected and approached with a critical mind. Other documents which were analysed were learners' note books, to get information on the frequency of written work and the amount of work allocated by teachers to students, as well as the regularity of such assigned work. Data were also sought on the consistency of the teachers' marking of work.

In this study the researcher adopted the simple observation method to collect data from schools on the implementation of the Life Orientation (LO) curriculum by high school teachers. The researcher listened to and observed (one lesson per school) how teachers implemented the Life Orientation (LO) curriculum in the classroom and how learners responded. The researcher recorded observations on a specially constructed data sheet. This data collection method allowed directness. Participants were not asked about their views, feelings or attitudes; they were listened to and watched while doing what they normally do. Observation was used to explore questions that were uncomfortable for participants to discuss. Data from observation contrasted with, and complemented, information obtained by interviews and document analysis.

\subsection{Participants}

The sample in this study were 48 participants, six principals, six Life Orientation (LO) teachers and thirty-six learners in six selected high schools in the Fort Beaufort Education District in the Eastern Cape - the district that the researcher is most familiar with. Teachers who were most experienced in the teaching of Life Orientation (LO) were selected. The six high schools were selected by means of purposive sampling within each of the six high school clusters in the district to avoid possible bias in selection - one high school from each cluster. The principals of these high schools were interviewed. Gatekeepers such as principals and other colleagues were consulted to identify the six teachers. Three learners each within Grades 11 and 12 were purposively selected, based on their behaviour and contributions noticed during the classroom observation. Thus the schools, principals, teachers and learners were all purposively selected.

\subsection{Procedures}

The researcher sought permission from the Provincial Department of Education to carry out the study. Furthermore, the researcher sought permission from the principals of each school selected to conduct research in their schools, arrange the dates for conducting the interviews and to interview participants. The researcher, although not a South African, did not find it difficult to interact with the participants. The fact that the learners were all accustomed to using English as the language of learning and teaching meant that interviews could be comfortably conducted in that language rather than in local languages.

\section{Findings}

This study endeavoured to respond to the main research question, which sought to investigate the implementation of the Life Orientation (LO) curriculum in high schools in the Fort Beaufort Education District. However, this article reports on one of the sub-questions that sought to find out how learners perceive the Life Orientation (LO) programmes. The findings of the study are discussed below. In the study, learners' focus groups are abbreviated as FG.

\subsection{What learners have learnt about drug abuse}

According to Burnett, 1998; Department of Health, 1998; Filsher, Reddy, Muller and Lombard, 2003, some South African adolescents frequently engage in a range of high-risk activities. Some young people use alcohol, tobacco and other drugs, engage in unprotected sex, have unhealthy dietary behaviours and are both perpetrators and victims of violence. It emerged from this study that there were learners who claimed that LO lessons had sensitized them to drug abuse in that some of them had stopped taking drugs, partly because of their knowledge of the effects of drugs abuse. Others, on the other hand, claimed that the knowledge of drug abuse exposed them to the temptation to abuse drugs. The following are some of their comments:

FG3: "We learnt that drugs are bad and can affect the way we think... Drugs can make you do things you are not meant 
to do, like crime, and rape."

FG6: "LO tells us that drug abuse is wrong... We should keep away from it because of its bad effect on our studies, families and community."

Learners were further asked to explain how knowledge of drug abuse had influenced their thinking. One learner from Focus Group 5, who was a drug survivor, revealed during the focus group interviews that:

FG5: "I used to be involved in drugs and drinking with my older friends, but with the knowledge of drug abuse in LO, I had to stop because it made me do bad things, disrespect my parents and people in the community. I had to stop when I realized it was destroying me. It affected my plans negatively, and did not let me achieve my goals. I had to apologize to my parents and focus on my studies."

It was indicated that some learners' knowledge base about drug abuse was strengthened through the teaching of LO. For other learners who claimed that LO lessons had sensitized them to drug abuse, it is obvious that saying such things in an interview does not mean that what these learners have learnt will be proof against their abusing drugs or alcohol in tempting circumstances. All it does is indicate that they have at least been taught about and made aware of the problems that can accompany drug and alcohol abuse.

\title{
3.2 Influence of sexuality education on learners' attitudes or behaviour
}

The study also explored the knowledge learners had gained from sexuality education, and how it had influenced their attitudes or behaviour. In the focus group interviews with learners, they made the following comments:

\begin{abstract}
"We have knowledge about sex... LO helps us to understand the disadvantages of early sex, like pregnancy, STI, HIV...we also know that sex is good only in marriage, and we must wait for the right time... We have also learnt to use a condom during sex." (FG4)
\end{abstract}

FG1: "We have learnt that sexual harassment and abuse can happen in the family and not only with strangers... We have learnt to protect ourselves from being raped by avoiding provocative dressing... Also, we learnt to abstain from sex in relationships because condoms are not $100 \%$ safe."

The focus group discussion on this section establishes that most of these learners may be sexually active, and that while they might be confused by myriad information from different sources, they have some ideas of their own with regard to issues of sex and sexual relations. Also, like many adults, their knowledge does not prevent them from bad choices and inappropriate sexual behaviour. The discussions further show that LO teaching is often a reinforcement of what they have already known, perceived or partially understood about sexual activities. The researcher realized from their expressions that there were a few of the focus group members who were not as informed as their counterparts, even those with a similar background. This group, usually female learners, apparently found some of the information in LO class useful in filling out their knowledge, especially about sexual relations with the opposite sex. The following are their comments:

\footnotetext{
"Yes, we learnt about diseases like STI and HIV, that can be contacted through sex... We learnt that if we want to have sex, we must use condoms... Also we are aware of ABC, (abstain, be faithful and condoms)... Abstaining is the best option, for it will make us wait for the right time." (FG5)

FG6: "Yes, we love to do it, but through LO we have learnt to wait until we are ready... it is not about penetration but about the values being lost... And if we cannot wait, we can use condoms... LO has taught us to step aside from peer pressure of wanting to practice sex... We get alternatives to love through sex in LO class, like holding hands and walking together.... going to bed is not a way of showing your love to someone."
}

It was also indicated that learners had benefited from the information they had received in sexuality education in relation to their attitudes or behaviour in matters of sex. This study revealed that sexuality education had, for instance, helped learners to understand that sexual harassment could happen within the family as well as with strangers. The finding of this study tends to support the findings of Rambiyana (2001:57) whose study indicated that the provision of sexuality education can help to reduce incidents of child sexual abuse. Further, it can also limit the spread of HIV-AIDS. Fay and Gordon (1989:215) also argue for sexuality education in schools, asserting that this is too important a matter to be left to chance, superstition, myth, peers and the media. 


\title{
3.3 The inclusion of Life Orientation as part of the school curriculum
}

The study sought the views of participant learners on whether they thought the inclusion of Life Orientation in the school curriculum was a good idea. The following are some of the focus groups' overwhelmingly positive comments on the inclusion of LO in the curriculum.

The following comments were made in FG1:

\begin{abstract}
"Having LO as part of the school curriculum is great; we are enjoying it... It makes us to be aware about everything concerning life... It helps us understand the ways of life... It prepares us for the world so that when we finish school, we will be able to know how to deal with things... LO also helps teenagers to be aware of things they are expected to go through in life. This will enable them to be well acquitted about life [sic] and enable them to make right decisions." FG3: "Yes. It is good that LO is taught in schools as part of the school curriculum because it helps to develop knowledge about oneself and to acquire the skills needed to socialize with others... Having LO as part of the school curriculum helps one develop positive attitudes toward physical activities and fitness."

FG6 saw LO as supplementing the parental or guardian role: "Many parents find it hard to tell their children about the things that happen in their lives, like sex, relationships and drugs, but through LO these things are taught."
\end{abstract}

The comments quoted above represent the consensus of the group, as far as the researcher could judge. The researcher noted in the course of discussion that two, three or more members of the group usually agreed on the same point, although they expressed them differently. In this section, most of the comments showed learners' positive claims about LO.

\subsection{Learners' perceptions of the knowledge they gain about HIV/AIDS}

The study sought, among other things, to investigate learners' perceptions of the knowledge they gain about HIVIAIDS and the value of this knowledge to them. All the participant learners showed a fair knowledge of HIV, its causes, symptoms, consequences and treatment, etc. The following were typical comments:

"With the knowledge of HIV, we now use condoms when having sex. We do not share objects like needles, tooth brush and razor blade." (FG1)

"We know that HIVIAIDS is an incurable disease, which kills... If one has it, one has to live a healthy life and one can live longer, but if the person does not accept it, the person may die." (FG3)

It was evident from the learner focus group discussions that some of the learners were sexually active, and that condoms were a popular commodity among them. This exposure may be partly attributed to LO lessons. It can be concluded that LO teaching on HIVIAIDS has helped to reinforce a sense of the importance of using condoms among the learners.

This study also found that the learners had acquired a fair knowledge of HIVIAIDS, and that their better knowledge of HIV was at least partly derived from LO lessons. Some of the learners said that the knowledge of HIV infections had led them to use condoms when having sex, not to share sharp objects, to wear gloves when in contact with a bleeding person, and to be faithful to their partners. The findings in this study are in line with Cromhout, (2005), who found that learners seemed to have internalised the knowledge taught, and achieved confidence and a degree of mastery of the issues surrounding HIVIAIDS. The major discovery coming out of the focus group discussions on this issue is that through their LO lessons, the learners had developed a reasonable awareness of the basic facts surrounding HIVIAIDS, and of what their response should be towards the disease and those infected. The following were typical comments:

"We realized that having HIVIAIDS infection does not mean the carrier is sleeping around and that how one gets infected does not matter, but what one does about it... We must not judge HIVIAIDS infected persons, but encourage them to live their lives by taking their drugs and moving on with their lives... This knowledge helps to equip ourselves against HIVIAIDS and to help our families and friends who may be infected." (FG6)

"With the knowledge of HIV, we now use condoms when having sex. We do not share objects like needles, tooth brush and razor blade." (FG1) 


\section{Conclusion}

It was found that some of the learners' exposure to knowledge of drug abuse, sex and other high-risk activities were widened partly as a result of the teaching they received in LO. This raises the question of: Are learners' being misguided? LO is specifically intended to help learners face and cope with problems, such as drug abuse, AIDS, peer pressure, and STDs as well as societal issues and problems such as career choices, crime, and corruption. The assessment standards in the National Curriculum Statement $(2002 ; 2003)$ assert that learners are expected to be able to solve or at least manage these problems in constructive ways. According to Burnett (1998); Department of Health (1998); and Filsher et al. (2003), South African adolescents frequently engage in a range of high-risk activities. Young people use alcohol, tobacco and other drugs, engage in unprotected sex, have unhealthy dietary behaviours and are both perpetrators and victims of violence. This study has shown research findings which indicate that most of the learners had claimed to benefit from LO lessons. Although many learners professed to be positive about LO in their responses, it is difficult to determine how honest they were being regarding these issues. This finding would at least to some extent support the study conducted by Theron (2008), who found that a sample of Grade 9 township learners valued LO. Even though learners were positive about the subject, it was not evident that they applied what they learned to their lives, which is a concern also mentioned by Prinsloo (2007:165).

It was found that some learners were in a sense contradicting themselves in the focus group interviews. Almost all the learners claimed that they liked LO, but some of them gave the impression that they actually engaged in risky behaviour that had been discussed in LO.

\section{Recommendations}

- Incentives should be provided to encourage teachers or would-be teachers to become qualified Life Orientation teachers. Potential Life Orientation teachers should be identified by schools to be retrained and acquire further skills as specialised LO teachers in order to avoid the issue of learners being inadvertently guided in their LO lessons.

- Curriculum developers should incorporate a more effective mechanism for measuring the impact of LO teaching on the learners as it seems that LO may have achieved more in the way of awareness creation in terms of imparting knowledge than it has in bringing about the behavioural changes that are expected.

- Learners should always be encouraged to contribute, or have input into, LO. Learners' opinions could sometimes be asked for on what they would like to do and achieve in the lessons and the physical activities.

\section{References}

Brezinka, W. (1994). Belief, morals, and education. Aldershot: Avebury.

Burnett, C. (1998). School violence in an impoverished South African community. Child Abuse and Neglect. 22(8): 789-795.

Collier, G., Tomlinson, P., and Wilson, J. (Eds.) (1974). Values and moral education in higher education. London: Croom Helm.

Coombe, C. (2002). Keeping the education system healthy: Managing the impact of HIVIAIDS on education in South Africa. Draft of a paper to be published by current issue in Comparative Education, e-journal of Teachers' College Press, Columbia University, New York.

Cromhout, J. (2005). Wildfire as an effective preventative intervention for HIVIAIDS among secondary school learners. Unpublished master's thesis.

Department of Education (1992). Education renewal strategy. Pretoria: Government Printers.

Department of Education (2007). National policy framework for teacher education and development in South Africa: "More teachers; better teachers." Pretoria: Government Printers.

Department of Health (1998). South African demographic and health survey. Pretoria: Government Printers..

Eggen, P. and Kauchak, D. (1997). Educational psychology: Windows on classrooms. Upper Saddle River, NJ: Prentice Hall.

Engelbrecht, C. (1998). Society as a socio-educative arena. Study guide for socio-education. Pretoria: University of South Africa.

Fay, J. and Gordon, S. (1989). Moral sexuality education and democratic values. Theory into Practice. 28: 211-216.

Flisher, A., Reddy, P., Muller, M., \& Lombard, C. (2003). Sexual behaviour of Cape Town high-school students. South African Medical Journal. 93(7): 537-541.

Krathwhol, D. (1993). Methods of educational and social science research. London: Longman.

Le Roux, J. (Ed.) (1994). The black child in crisis: A socio-educational perspective. Pretoria: Van Schaik Publishers.

Mouly, G. (1978). Educational research: The art and science of investigation. Boston: Allyn and Bacon.

Mwamwenda, T. (2004). Educational psychology: An African perspective. Sandton: Heinemann.

National Education Policy Investigation. (1993). The framework report. Cape Town: Oxford University Press. 
Pretoria News. (2006). City residents tired of crime. 12 September.

Pretorius, J. (1998). Socio-pedagogics. Pretoria: Van Schaik Publishers.

Prinsloo, E. (2005). Socio-economic barriers to learning in contemporary society. In: E. Landsbergh (Ed.) Addressing barriers to learning: A South African perspective. Pretoria: Van Schaik Publishers.

Prinsloo, E. (2007). Implementation of Life Orientation programmes in the new curriculum in South African schools: Perceptions of principals and Life Orientation teachers. South African Journal of Education. 27(1): 155-170.

Rambiyana, G. (2001). Parents' expectations of public schooling in the Northern Province of the Republic of South Africa. D.Ed. thesis, Rand Afrikaans University, Johannesburg.

Republic of South Africa (2000). Education in a global era. Paper delivered at fourteenth Conference of Commonwealth Education Ministers, Canada.

South African Department of Education. (2003). National Curriculum Statement, Grades10-12: Life Orientation. Pretoria: Government Printers.

South African Department of Education. (2003). Revised National Curriculum Statement, Grades R-9 (schools). Teachers' guides for the development of learning programmes. Policy guidelines: Life Orientation. Pretoria: Government Printers.

Sutherland-Addy, E. (2005). Gender equity in junior and senior secondary education in Sub-Saharan Africa. Dakar: Forum for African Women Educationalists (FAWE) http://www.fawe.org/home/index.asp.

Theron, L. (2008). The Batsha Life Orientation study: An appraisal by Grade 9 learners living in townships. Education as Change. 12(1): $45-65$ 